\title{
Semen quality and sex hormones among mild steel and stainless steel welders: a cross sectional study
}

Jens Peter Bonde

\begin{abstract}
Welding may be detrimental to the male reproductive system. To test this hypothesis, semen quality was examined in 35 stainless steel welders, 46 mild steel welders, and 54 nonwelding metalworkers and electricians. These figures represent a participation rate of $37 \cdot 1 \%$ in welders and $36.7 \%$ in non-welding subjects. The mean exposure to welding fume particulates was $1.3 \mathrm{mg} / \mathrm{m}^{3}(\mathrm{SD} 0.8)$ in stainless steel welders using tungsten inert gas, $3.2 \mathrm{mg} / \mathrm{m}^{3}$ (SD 1.0) in low exposed mild steel welders using manual metal arc or metal active gas $(\mathrm{n}=31)$, and $4 \cdot 7 \mathrm{mg} / \mathrm{m}^{3}(\mathrm{SD} 2 \cdot 1)$ in high exposed mild steel welders $(n=15)$. The semen quality of each participant was defined in terms of the mean values of the particular semen parameters in three semen samples delivered at monthly intervals in a period with occupational exposure in a steady state. The sperm concentration was not reduced in either mild steel or stainless steel welders. The sperm count per ejaculate, the proportion of normal sperm forms, the degree of sperm motility, and the linear penetration rate of the sperm were significantly decreased and the sperm concentration of follicle stimulating hormone (FSH) was non-significantly increased in mild steel welders. A dose response relation between exposure to welding fumes and these semen parameters (sperm count excepted) was found. Semen quality decreased and FSH concentrations increased with increasing exposure. Significant deteriorations in some semen parameters were also observed in stainless steel welders. An analysis of information from questionnaires obtained from the whole population including subjects who declined to participate indicated an underestimation of effects due to selection bias. Potential confounding was treated by restriction and statistical analysis. The results support the hypothesis
\end{abstract}

Department of Occupational Medicine, Hospital of Aalborg, and Institute of Social Medicine, University of Aarhus, Denmark

J P Bonde that mild steel welding and to a lesser exten $\vec{t}$ stainless steel welding with tungsten inert gaळ is associated with reduced semen quality as exposures in the range of the Danish proces specific threshold limit values of welding.

In industrialised countries $0 \cdot 2-2 \%$ of the laboup force is engaged in metal welding. ${ }^{1}$ The material most commonly welded is mild steel, but welding of stainless steel and high performance alloyed steel is also widely practised. It is estimated that a large number of welders using the most common welding methods, manual metal arc (MMA) and metal active or inactive gas (MAG or MIG), are exposed tळ welding fumes at concentrations far exceeding the threshold limit values proposed by the Nationa\& Institute of Security and Health. ${ }^{12}$

In recent years several Danish studies have suggese ted that welding may have deleterious effects on th ${ }^{\circ}$ male reproductive system. Two case-control studies. of infertile couples found increased risk of reduce $\bar{\Phi}$ semen quality ${ }^{34}$ and three studies with differen methodological approaches have reported associa tions between paternal exposure to welding and delayed conception and reduced fertility. ${ }^{35}$ Preliminary results of a cross sectional study of stainless steel welders, however, did not indicate reduced semen quality. ${ }^{7}$

Several exposures in the occupational setting o甲 welders constitute hypothetical hazards to the male reproductive system. Toxic metals such as mangan $\mathrm{O}$ ese, hexavalent chromium, nickel, and vandium ing welding fumes, and organic compounds in shope primers occur partly in water soluble and respirable forms, and a substantial fraction is absorbed in the pulmonary circulation. ${ }^{8}$ Stainless steel welding fumes have mutagenic and cytotoxic effects in in vitres bioassay systems. These effects are mainly attribu요 table to hexavalent chromium and partly to nickel in various solubility states. ${ }^{19}$ In rodents it has beerw demonstrated by autoradiography that chromium? accumulates in the interstitial tissue of the testis. ${ }^{10} \mathrm{InO}$ a single and unconfirmed animal experiment man ganese was found to have a toxic effect on the testis and on spermatogenesis. ${ }^{11}$ Heat has a pronounced

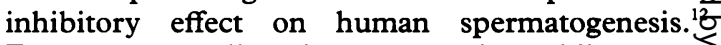
Exposure to radiant heat occurs in welding, par ticularly of preheated steel. 
The purpose of this study was to test the hypothesis that welding is detrimental to the male reproductive system. In a cross sectional design several semen parameters and testosterone, follicle stimulating hormone (FSH), and luteinising hormone $(\mathrm{LH})$ concentrations were estimated in mild steel welders using MMA and MAG, stainless steel welders using tungsten inert gas (TIG), and a referent group.

\section{Subjects and methods}

WORKPLACES AND EXPOSURE TO WELDING FUMES

Six workplaces located in Aalborg, Denmark were selected for the study (table 1). The five main types of welding processes were defined in terms of plant, type of steel, and welding method (quoted in table 1).
The time weighted average exposure to welding fume particulates was measured by taking a total of 45 full shift air samples in the breathing zone (inside the face mask) of randomly selected welders from each of the five welding categories. The samples were collected on filters (millipore filter AAWP ø $37 \mathrm{~mm}$, mean pore size $0.8 \mu \mathrm{m}$ ) with personal sampling pumps (Casella, $1.91 / \mathrm{min}$ ) that were calibrated against a gasmeter. The concentration of fume particulates in air was measured by the weight of the filter and the concentration of particular metals in air was determined by atomic absorption spectrometry.

Table 2 presents the results of the welding fume measurements. In mild steel welders the results were analysed in order to define predictors for total fume exposure in terms of plant and welding method. The MMA mild steel welders at plant B were significantly

Table 1 Characteristics of plants

\begin{tabular}{|c|c|c|c|c|c|}
\hline \multirow[b]{2}{*}{ Plant } & \multicolumn{5}{|l|}{ Characteristic } \\
\hline & Product & $\begin{array}{l}\text { No of } \\
\text { production } \\
\text { workers }\end{array}$ & Type of steel & $\begin{array}{l}\text { Welding } \\
\text { method }\end{array}$ & Welding workplaces \\
\hline A & Steel constructions for industry & 130 & Mild steel & $M M A^{\star}, M A G \star$ & Indoor, open, non-stationary \\
\hline B & Boilers for power stations & 348 & $\begin{array}{l}\text { Mild steel } \\
\text { Alloyed steel } \dagger\end{array}$ & $\begin{array}{l}\text { MMA }{ }^{\star}, M^{\star} G^{\star} \\
\text { TIG }\end{array}$ & $\begin{array}{l}\text { Indoor, open/confined, non- } \\
\text { stationary }\end{array}$ \\
\hline C & Equipment for food industry & 92 & Stainless steel & TIG* & Indoor, open, stationary \\
\hline $\mathrm{D} \S$ & Pumps & 54 & Stainless steel & TIG & Indoor, open, stationary \\
\hline $\mathbf{E} \|$ & Asbestos cement products & 21 & - & - & - \\
\hline $\mathbf{F} \|$ & Cement & 27 & - & - & - \\
\hline
\end{tabular}

*Welding fume measurements performed.

† Chromium nickel alloy comparable to stainless steel.

$\ddagger$ Welding fume measurements not performed. The exposure was comparable to the exposure at TIG stainless steel welding plant C.

$\S$ Only four persons had welding tasks.

|Only departments employing electricians addressed.

Table 2 Total fume and metal concentrations in workroom air collected with personal samplers by random selected mild steel and stainless steel tungsten inert gas welders

\begin{tabular}{|c|c|c|c|c|}
\hline & \multicolumn{2}{|c|}{ Mild steel welders } & \multirow[b]{2}{*}{ Stainless steel $\ddagger$ welders } & \multirow[b]{3}{*}{ p Value } \\
\hline & High exposed $\star$ & Low exposed $†$ & & \\
\hline & Mean (SD) & Mean (SD) & Mean (SD) & \\
\hline $\begin{array}{l}\text { Welding intermittence }(\%) \\
\text { Total fumes }\left(\mathrm{mg} / \mathrm{m}^{3}\right) \\
\text { Iron }\left(\mathrm{mg} / \mathrm{m}^{3}\right) \\
\text { Manganese }\left(\mu \mathrm{g} / \mathrm{m}^{3}\right) \\
\text { Copper }\left(\mu \mathrm{g} / \mathrm{m}^{3}\right) \\
\text { Chromium total }\left(\mu \mathrm{g} / \mathrm{m}^{3}\right) \\
\text { Chromium VI }\left(\mu \mathrm{g} / \mathrm{m}^{3}\right)\end{array}$ & $\begin{array}{rr}21.6 & (5 \cdot 0) \\
4.7 & (2 \cdot 7) \\
0.9 & (0.3) \\
132.1 & (102 \cdot 6) \\
7.3 & (1 \cdot 7) \\
3.0 & (1 \cdot 8) \\
2.0 & (1 \cdot 2)\end{array}$ & $\begin{array}{rr}18.0 & (9.6) \\
3.2 & (1.0) \\
1.0 & (0.5) \\
64.8 & (49.9) \\
14.9 & (10.4) \\
4.1 & (9.0) \\
1.2 & (1.2)\end{array}$ & $\begin{aligned} 14.5 & (8 \cdot 8) \\
1.3 & (0.8) \\
0.08 & (0.06) \\
4.0 & (2.1) \\
5.5 & (3.3) \\
14.8 & (11.4) \\
3.6 & (2.8)\end{aligned}$ & $\begin{array}{l}0.36 \\
0.05 \\
0.99 \\
0.03 \\
0.06 \\
0.09 \\
0.69\end{array}$ \\
\hline
\end{tabular}

^Results of seven random samples from MMA mild steel welders, plant $B$.

†Results of eight random samples from MAG mild steel welders, plant $B$.

†Seven samples from MMA welders, plant A, and eight samples from MAG welders, plant A.

§Results of 15 random samples from stainless steel welders using the TIG welding method, plant C.

||One way analysis of variance with logarithm transformed dependent variables, low exposed $v$ high exposed mild steel welders (stainless steel welders not included in this analysis).

Danish process dependent threshold limit values (1987) for total fume particulates are: TIG stainless steel; 2.6 mg/m³ $\mathbf{M A G}^{3}$ mild steel, $2 \cdot 8 \mathrm{mg} / \mathrm{m}^{3}$; MMA mild steel, $3 \cdot 1 \mathrm{mg} / \mathrm{m}^{3}$. 
Table 3 Study participation

\begin{tabular}{|c|c|c|c|c|c|}
\hline \multirow{3}{*}{$\begin{array}{l}\text { Occupation } \\
\text { Welding workers } \\
\text { Non-welding workers }\end{array}$} & \multicolumn{5}{|c|}{ No of subjects } \\
\hline & \multirow{2}{*}{$\begin{array}{l}\text { Source } \\
\text { population }\end{array}$} & \multirow{2}{*}{$\begin{array}{l}\text { Respondents } \\
\text { to questionnaire }\end{array}$} & \multirow{2}{*}{$\begin{array}{l}\text { Eligible† } \\
277 \\
125\end{array}$} & \multirow{2}{*}{$\begin{array}{l}\text { Potential } \\
\text { admittable } \\
129 \\
54\end{array}$} & $\begin{array}{l}\text { Actualફ } \\
\text { admitted }\end{array}$ \\
\hline & & & & & $\begin{array}{ll}81 & (79) \| \\
54 & (56) \|\end{array}$ \\
\hline Total & 672 & 537 & 402 & 183 & 135 \\
\hline
\end{tabular}

*Occupation classified as welding/non-welding in accordance with job category at time of study.

+ Respondents to the questionnaire, who met one or more of the following criteria, were defined as ineligible: age $>50$ years; occupation as truck driver, grinder, annealer, cutter, painter, degreaser, or rigger; vasectomised; recognised non-descended testis and single testicle treated for cancer or diabetes mellitus; treated with salazopyrine or chemotherapeutics; ceased welding work within the past two yearo before start of collection of semen samples.

$\$$ Eligible, who volunteered to deliver semen samples. of 135 actual admitted.

|Two workers (a driller and a machinist) were reallocated to a welding category in accordance with interview information.

more exposed to welding fume (mean $4 \cdot 7, \mathrm{SD} 2 \cdot 7$ ) than all other mild steel welders (MMA, plant A mean 3.1, SD 1.1; MAG, plant B mean 3.3, SD 1.3; MAG plant A mean $3 \cdot 1$, SD $0 \cdot 8$ ). For this reason, MMA mild steel welders at plant $B$ were designated as high exposed and all other mild steel welders as low exposed.

Table 4 Exposure classification of participants in semen study

\begin{tabular}{llcc}
\hline Exposure category & Welding method & \multicolumn{2}{c}{ No of subjects } \\
\hline Mild steel welders` & MMA, MAG, or both & 31 & 46 \\
$\quad$ Low exposed & MMA & 15 & \\
$\quad$ High exposed $\dagger$ & TIG & & 35 \\
Stainless steel welders & & & 54 \\
Referents $\ddagger$ & & 22 & \\
$\quad$ Electricians & & 16 & \\
Drillers & & 9 & \\
Machinists & 7 & \\
Unskilled & & & 135 \\
Total & & &
\end{tabular}

^Nine subjects had to a limited degree welded alloyed steel up to one month before the first semen sample.

†MMA mild steel welders, plant $B$.

$\ddagger$ No welding work for at least the last two years before the study.
SELECTION AND CLASSIFICATION OF PARTICIPANTS 은 A letter explaining the purpose of the study and a questionnaire were mailed to all 672 male workersc employed on 1 December 1986 . The workers werec addressed up to three times to enlist their cooperation. The response rate for the questionnaire wase $79 \%$ in welders and $83 \%$ in non-welding workers;:0 $248(36.9 \%)$ agreed to deliver three semen samples. The final study population comprising 135 subjects was defined by the eligibility criteria listed in table $3 . \frac{\partial}{0}$ Assuming a balanced distribution of non-eligiblea subjects among questionnaire respondents and non- $\frac{\mathbb{\Phi}}{\mathbb{Q}}$ respondents, the participation rate in the semen study was $37 \cdot 1 \%$ for welders and $36 \cdot 7 \%$ for nonwelding workers.

Information concerning occupational exposures, reproductive experience, urogenital disorders, and life style was obtained through structural interviews. The welders were grouped into mild steel and 3 stainless steel welders by information about type of steel welded in the three months preceding and during the study period (table 4). The mild steel welders were subdivided into a high and a low exposed group by plant and welding method? employed in accordance with the result of

\section{Table 5 Subject characteristics}

\begin{tabular}{|c|c|c|c|c|c|}
\hline Characteristic & $\begin{array}{l}\text { Mild } \\
(n=\end{array}$ & $\begin{array}{l}\text { steel welders } \\
\text { 46) }\end{array}$ & $\begin{array}{l}\text { Stainless steel welders } \\
(n=35)\end{array}$ & $\begin{array}{l}\text { Refer } \\
(n=\end{array}$ & ents \\
\hline 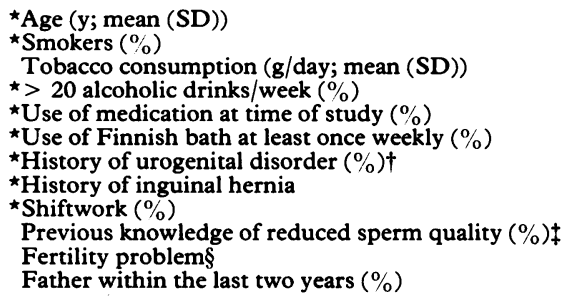 & $\begin{array}{r}33 \cdot 7 \\
47 \cdot 8 \\
6 \cdot 8 \\
17 \cdot 4 \\
15 \cdot 2 \\
13 \cdot 0 \\
0 \\
0 \\
26 \cdot 1 \\
4 \cdot 4 \\
17 \cdot 4 \\
4 \cdot 4\end{array}$ & $\begin{array}{l}(9 \cdot 2) \\
(7 \cdot 5)\end{array}$ & $\begin{aligned} 30 \cdot 6 & (7 \cdot 7) \\
48 \cdot 6 & \\
7 \cdot 5 & (8 \cdot 5) \\
25 \cdot 7 & \\
14 \cdot 3 & \\
8 \cdot 6 & \\
2 \cdot 9 & \\
5 \cdot 7 & \\
25 \cdot 7 & \\
2 \cdot 9 & \\
11 \cdot 4 & \\
14 \cdot 3 & \end{aligned}$ & $\begin{array}{r}34 \cdot 5 \\
51 \cdot 9 \\
6 \cdot 0 \\
13 \cdot 2 \\
7 \cdot 4 \\
14 \cdot 8 \\
9 \cdot 3 \\
13 \cdot 0 \\
24 \cdot 1 \\
5 \cdot 6 \\
18 \cdot 5 \\
13 \cdot 0\end{array}$ & $\begin{array}{r}(8 \cdot 7 \\
(8 \cdot 1\end{array}$ \\
\hline
\end{tabular}


Table 6 Semen sample characteristics

\begin{tabular}{|c|c|c|c|}
\hline Characteristic & $\begin{array}{l}\text { Mild steel welders } \\
(n=46)\end{array}$ & $\begin{array}{l}\text { Stainless steel welders } \\
(n=35)\end{array}$ & $\begin{array}{l}\text { Referents } \\
(n=54)\end{array}$ \\
\hline $\begin{array}{l}\text { No delivering first semen sample } \\
\text { No delivering second semen sample } \\
\text { No delivering third semen sample } \\
\text { Spillage at ejaculation }(\%) \dagger \\
\star \text { Fever in previous three months }(\%) \\
\star \text { Leucocytospermia }(\%) \\
\text { Days abstinence (mean (SD)) } \ddagger \\
\star \text { Hours from semen sample collection } \ddagger \text { to analysis } \\
\text { (mean (SD)) }\end{array}$ & $\begin{array}{rr}44 & \\
41 & \\
35 & \\
26 \cdot 0 & \\
17 \cdot 4 & \\
10 \cdot 9 & \\
3 \cdot 7 & (1 \cdot 3) \\
& \\
2 \cdot 3 & (0 \cdot 4)\end{array}$ & $\begin{aligned} 35 & \\
31 & \\
27 & \\
51 \cdot 4 & \\
2.9 & \\
28.6 & \\
5.7 & (8.9) \S \\
2.4 & (0.4)\end{aligned}$ & $\begin{array}{rr}53 & \\
52 & \\
35 & \\
27 \cdot 1 & \\
6 \cdot 8 & \\
6 \cdot 8 & \\
3.9 & (1.9) \\
& \\
2 \cdot 4 & (0.4)\end{array}$ \\
\hline
\end{tabular}

^Parameters included in multiple regression analysis.

$t^{\circ}{ }_{0}$ Subjects with at least one semen sample with spillage.

†Mean of all semen samples in each exposure category.

$\S$ The high mean abstinence period and SD reflect two subjects with outlying abstinence periods ( 42 and 90 days). After exclusion of these, the mean abstinence period was $3 \cdot 4(2 \cdot 1)$ days.

measurements on the welding fumes (table 2). The exposed and non-exposed groups were generally similar in personal characteristics (table 5), with the exception of history of urogenital disorder and inguinal hernia, which were more prevalent in referents, and history of urethritis, which was more prevalent among the welders.

\section{SEMEN COLLECTION AND ANALYSIS}

The participants were asked to collect three samples of semen at monthly intervals. These were delivered at home in the morning by masturbation into a sterile plastic jar after preferably three days of abstinence. The samples were brought to the workplace by the participants and transported to the laboratory within two hours of collection. Time of ejaculation, abstinence period, spillage (if any), and fever during the last three months were recorded by the subject (table 6). All semen samples were processed and analysed blindly by the same experienced laboratory assistant at the infertility clinic of the Hospital of Aalborg. Volume, total sperm count, sperm concentration, proportion of abnormal sperm forms, proportion of motile sperm, a semi-quantitative measure of the degree of motility, and linear sperm penetration rate in eggwhite were examined in accordance with the World Health Organisation guidelines for the examination of human semen. ${ }^{13}$ The number of immature sperm cells and the number of leucocytes were scaled into four categories; none, few, some, and many.

Blood samples were collected by venepuncture between 9.00 and $12.00 \mathrm{am}$. Serum concentrations of testosterone, FSH, and $\mathrm{LH}$ were determined by radioimmunossay.

\section{ANALYSIS AND STATISTICAL METHODS}

The distributions of semen parameters in stainless steel workers and mild steel welders were compared separately with the distributions in the referent group by analysing the means of the parameters in the three samples of each subject.
The distributions of the mean values were tested for normality using Shapiro-Wilk and Kolomogorov statistics. ${ }^{14}$ If necessary, data were transformed to obtain normality or homogeneity of the residual variances. A logistic transformation was used in the case of proportions (percentage of motile sperm and normal forms). Testosterone, FSH, and LH concentrations, and semen volume were distributed with positive skewness and were transformed to natural logarithms. Sperm count per ejaculate and sperm concentration were transformed by the square root function.

Between group differences were tested by one way analysis of variance. ${ }^{15} \mathrm{~A}$ dose response analysis in mild steel welders was performed by least square linear regression. ${ }^{15}$ The level of exposure to welding fume was expressed as a continuous variable taking the values of five (high exposure group), three (low exposure group), and nought (referents) to correspond to the mean levels of total fume exposure (table 2 ). The stainless steel welders were not included in this analysis because of incomparability of exposures in the welding of mild steel and stainless steel.

The analyses of semen volume and total sperm count per ejaculate were restricted to semen samples without spillage. Total sperm count per ejaculate and sperm concentration were adjusted for period of abstinence before the mean values for each subject were calculated. An increase in sperm concentration of 4.5 million a ml day of abstinence in the interval of nought to seven days was found in the study population. This figure was used to adjust the sperm concentration to three days of abstinence. The potential confounding variates listed in tables 5 and 6 were treated in the analysis by multiple regression techniques. ${ }^{15}$ Covariates were considered for inclusion in the regression model using a backward stepwise technique with exposure forced into the model. Variables were excluded one by one from the model if the $p$ value of the regression coefficient was higher than 0.10 and if the effect of the covariate was negligible. 
In the analysis of abnormal sperm morphology, the overall significance of the exposure variable on the group of closely correlated dependent variables representing the different abnormal forms was tested by the MANOVA procedure. ${ }^{15}$ Discrete effect variables-for example, degree of motility and occurrence of immature sperm forms-were analysed by two tailed $\chi^{2}$ test and Fisher's exact test.

\section{Results}

Table 7 gives the results of sperm parameters and serum concentrations of sex hormones in mild steel and stainless steel welders. Low and high exposed mild steel welders were identified by measurements of welding fumes. Table 8 gives the results of the dose response analysis for mild steel welders and referents. Only parameters that differed significantly

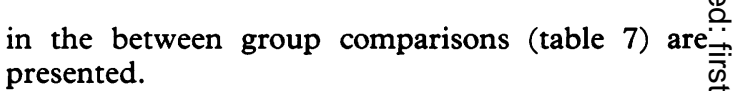

Welding exposure had no overall significant effecto on the distribution of specific abnormal forms of mature sperm according to the World Health Organ- $-\overline{\bar{s}}$ isation classification in either mild steel or stainless $\frac{\varnothing}{\Omega}$ steel welders. A regression analysis of the actual leveloy of semen quality on the cumulative welding exposures (years of welding) showed no significant differences. between any of the semen characteristics and years of $\vec{\sim}$ welding. The proportion of normal sperm forms and ${ }^{\omega}$ motile sperm were, however, negatively but insignificantly related to years of welding stainless steel. A $\rightrightarrows$ positive but also insignificant trend was observed $+\overrightarrow{-}$ between the actual level of the same two spermo characteristics and years since the last period of ${ }^{\circ}$ welding stainless steel in 28 former stainless steel welders.

Table 7 Semen parameters and sex hormones in mild steel welders, stainless steel welders, and referents

\begin{tabular}{|c|c|c|c|c|c|}
\hline Parameter & $\begin{array}{l}\text { Mild steel } \\
\text { welders }(n=46)\end{array}$ & $\begin{array}{l}\text { Stainless steel } \\
\text { welders }(n=35)\end{array}$ & $\begin{array}{l}\text { Referents } \\
(n=54)\end{array}$ & $p$ Value $^{\star}$ & $p$ Value $\dagger$ \\
\hline $\begin{array}{l}\text { Sperm count per ejaculate (millions): } \\
\text { Mean (SD) } \\
\text { Adjusted mean (SD) }+\S\end{array}$ & $\begin{array}{ll}153 & (85) \\
148 & (85)\end{array}$ & $\begin{array}{ll}138 & (63) \\
135 & (58)\end{array}$ & $\begin{array}{ll}184 & (114) \\
190 & (113)\end{array}$ & $\begin{array}{l}\text { NS } \\
<0.05\end{array}$ & $\begin{array}{l}<0.05 \\
<0.05\end{array}$ \\
\hline $\begin{array}{l}\text { Semen volume (ml): } \\
\text { Mean (SD) } \\
\text { Adjusted mean }(\mathrm{SD})+\$\end{array}$ & $\begin{array}{ll}2 \cdot 8 & (1 \cdot 6) \\
2 \cdot 8 & (1 \cdot 6)\end{array}$ & $\begin{array}{ll}2 \cdot 4 & (1 \cdot 1) \\
2 \cdot 6 & (1 \cdot 1)\end{array}$ & $\begin{array}{ll}3 \cdot 1 & (1 \cdot 3) \\
3 \cdot 3 & (1 \cdot 4)\end{array}$ & $\begin{array}{l}\text { NS } \\
\text { NS }\end{array}$ & $\begin{array}{l}<0.05 \\
<0.05\end{array}$ \\
\hline $\begin{array}{l}\text { Sperm concentration (millions): } \\
\text { Mean (SD) } \\
\text { Adjusted mean (SD) } \\
\text { Sperm concentration }<20 \text { million ( } \% \text { of } \\
\text { subjects) }\end{array}$ & $\begin{array}{rr}57 \cdot 9 & (24 \cdot 8) \\
56 \cdot 1 & (24 \cdot 0) \\
6 \cdot 5 & \end{array}$ & $\begin{array}{c}58 \cdot 4(16 \cdot 7) \\
56 \cdot 4(15 \cdot 3) \\
2 \cdot 9\end{array}$ & $\begin{array}{c}58 \cdot 6(23 \cdot 9) \\
55 \cdot 1(24 \cdot 3) \\
5.6\end{array}$ & $\begin{array}{l}\text { NS } \\
\text { NS } \\
\text { NS }\end{array}$ & $\begin{array}{l}\text { NS } \\
\text { NS } \\
\text { NS }\end{array}$ \\
\hline 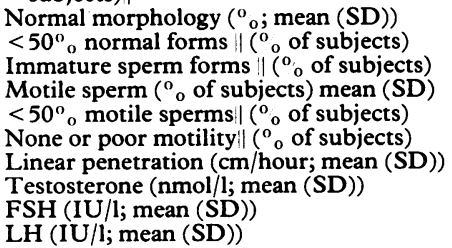 & $\begin{array}{l}59 \cdot 4(18 \cdot 5) \\
21 \cdot 7 \\
8 \cdot 7 \\
54 \cdot 8(11 \cdot 8) \\
39 \cdot 1 \\
45 \cdot 7 \\
3 \cdot 5(0 \cdot 7) \\
18 \cdot 6 \quad(6 \cdot 4) \\
5 \cdot 7 \quad(3 \cdot 5) \\
7 \cdot 1 \quad(2 \cdot 9)\end{array}$ & $\begin{array}{rr}65 \cdot 8 & (15 \cdot 7) \\
14 \cdot 3 & \\
17 \cdot 1 & \\
51 \cdot 0 & (15 \cdot 7) \\
31 \cdot 4 & \\
51 \cdot 4 & \\
3 \cdot 8 & (0 \cdot 7) \\
17 \cdot 3 & (5 \cdot 8) \\
4 \cdot 4 & (5 \cdot 1) \\
6 \cdot 1 & (2 \cdot 4)\end{array}$ & $\begin{aligned} 66 \cdot 7 & (17 \cdot 1) \\
14 \cdot 8 & \\
3 \cdot 7 & \\
57 \cdot 7 & (14 \cdot 8)) \\
22 \cdot 2 & \\
22 \cdot 2 & \\
3 \cdot 8 & (0 \cdot 5) \\
21 \cdot 2 & (8 \cdot 0) \\
4 \cdot 9 & (2 \cdot 8) \\
7 \cdot 2 & (2 \cdot 7)\end{aligned}$ & $\begin{array}{l}<0.01 \\
\text { NS } \\
\text { NS } \\
\text { NS } \\
\text { NS } \\
<0.05 \\
<0.05 \\
\text { NS } \\
\text { NS } \\
\text { NS }\end{array}$ & $\begin{array}{l}\text { NS } \\
\text { NS } \\
<0.05 \\
<0.05 \\
\text { NS } \\
<0.01 \\
\text { NS } \\
<0.05 \\
\text { NS } \\
\text { NS }\end{array}$ \\
\hline
\end{tabular}

^Adjusted $\mathrm{p}$ value, mild steel welders $v$ referents.

†Adjusted $\mathrm{p}$ value, stainless steel welders $v$ referents.

tExclusion of semen samples with spillage.

$\S$ Adjusted for abstinence period.

|The parameter reduced in both first and second semen sample.

NS; $\mathrm{p}>0.05$.

Table 8 Trend analysis of selected semen parameters and hormones in mild steel welders

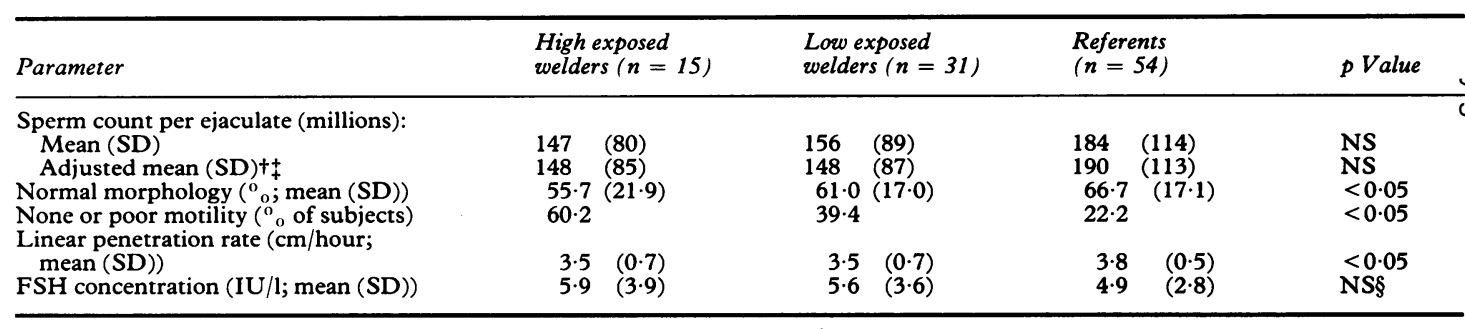

$\star$ Test for linear trend, least squares linear regression; adjusted p value and $\chi^{2}$ test (degree of motility).

+ Exclusion of semen samples with spillage.

+ Adjusted for abstinence period.

$\$ \mathrm{p}=0.06$. 


\section{Discussion}

This study suggests that current welding of mild steel is related to a moderate decrease in sperm count per ejaculate, proportion of normal sperm forms, motility, and linear penetration rate, and to a borderline significant increase in concentration of FSH in serum. A dose response relation between total exposure to welding fumes and these semen parameters (sperm count excepted) was found. The semen parameters decreased and FSH concentration increased with increasing exposure to welding fumes. Compared with the referent group, the stainless steel welders had significantly decreased semen volume, total sperm count, proportion of motile sperm, motility, and concentration of testosterone in serum.

A distinction between mild steel and stainless steel welders has been made in all analyses; exposures were not comparable owing to qualitative differences in composition of the fumes. ${ }^{12}$ Even the composition of the fume emissions associated with welding of one type of steel may vary depending on welding method and a number of other factors that characterise the welding process. ${ }^{12} \mathrm{~A}$ quantitative measure of exposure to mild steel fumes would, optimally, require a standardisation with regard to differences in relative concentrations of the single constituents of the fume particulates. Such a measure would be difficult to develop due to limited knowledge of spermatotoxic effects of the different substances. In this study, the approach adopted in the grouping of mild steel welders into high and low exposed was simply to employ the total exposure to fumes. Although the "total exposure to welding fumes" is not a chemically well defined entity, the differences in composition of welding fumes in high and low exposed groups (table 2) and within the low exposed group is small.

The order of magnitude of the detected deteriorations in semen quality ranged from $28 \%$ (sperm count) to $8 \%$ (linear penetration rate) and no effects on sperm concentration were observed in any group of welders. The moderate size of the effects and the absence of specific biological hypotheses concerning particular effects on the individual semen parameters necessitates a careful examination of possible sources of bias.

The participation rate in the study was the same in welders and referents but was, nevertheless, rather low. For that reason selection bias might easily have been introduced. This problem was addressed by an analysis of the information obtained from questionnaire (response rate $80 \%$, table 3). Previous knowledge of reduced semen quality (obtained at for example an earlier infertility examination) and history of urogenital disorder occurred at a higher rate in participating referents (odds ratio $(O R)=4 \cdot 2$, $\mathrm{p}<0.05)$ in comparison with non-participating referents $(\mathrm{OR}=3.2, \mathrm{p}<0.05)$. This selection was not seen in the welders. For that reason bias towards the null hypothesis is probable.

The referents were selected from the same geographical, occupational, and social setting as the welders to ensure an optimal contrast with respect to the exposure of interest. Indirect (bystander) exposure of referents could, however, blur the contrast. This possibility is hardly of importance as no differences in semen quality were observed between the internal referents (from the metal industrial plants) and the external referents (electricians from non-metal industrial plants).

The semen parameters were analysed by calculation of the arithmetic mean of several samples from each subject. This simple analytical approach reduces statistical power. In particular, selection bias is introduced if delivery of succeeding samples is dependent on exposure and semen quality. Drop out occurred in all three exposure groups (table 6). For that reason all associations were reanalysed restricting the analysis to the semen sample first delivered. All reported associations were confirmed, and in most cases even stronger associations were found.

The exposed and unexposed groups were similar with respect to distribution of age and tobacco smoking, but different with regard to consumption of alcohol and Finnish bathing (table 5). No effect of smoking, consumption of alcohol, or Finnish bathing was observed, although all these factors have been reported to cause deterioration in semen quality. ${ }^{1216}$ None of these factors changed the relations observed when included in the multivariate regression analysis.

The period of sexual abstinence has been reported to be linearly related to increase in semen volume and sperm concentration in the interval nought to seven days, whereupon the effect decreases. The period of abstinence had a balanced distribution in exposed and unexposed subjects (table 6), and is unlikely to be a confounding factor unless the self reported data on duration of abstinence are unreliable. The participants were informed that correct answers were of major importance and that periods of abstinence deviating from the three days preferred would not invalidate the study. The distribution of periods of abstinence appear reasonable and do not suggest unreliable answers.

The age of the sample at analysis is known to strongly affect sperm motility and velocity, ${ }^{12}$ but there were no apparent differences between the exposure groups. It is difficult to obtain optimal standardisation of the sampling procedures, however, in a field in which the samples are delivered at home but analysed after transport to the laboratory. The results regarding parameters of motility should, therefore, be interpreted with caution.

Both fever during the months preceding the 
delivery of a semen sample and leucocytes in the semen were strongly related to changes in several sperm parameters and both factors had an unbalanced distribution in the exposuure groups. Nevertheless, the effect of exposure to welding remained even when controlling these covariates in a multiple regression analysis.

The slight increase in FSH concentration in the mild steel welders may reflect a compensatory response to a partly impaired spermatogenesis. ${ }^{19}$ The serum concentration of FSH was significantly correlated to total sperm count per ejaculate $(\mathrm{r}=-0.41, \mathrm{p}<0.01)$, and proportion of normal sperm forms $(r=-0.34, p<0.05)$ in mild steel welders, whereas this was not the case in the referent group $(r=-0.11, p=0.43$ for total sperm count and $r=0.12, p=0.42$ for sperm forms). This finding supports the interpretation that the increase in FSH concentration indicates diminished negative feed back from the seminiferous tubules.

In summary, no positive bias has been found. The significance of uncontrolled selection, the hypothetical role of unrecognised determinants, and residual confounding due to loss of information introduced by binary scaling of most potential confounders cannot, however, be completely precluded. Considering the results concerning welding of mild steel, the dose response relation and the consistency of sperm and FSH findings add considerably to the reliability of the results. The findings with stainless steel welders are more dubious. The stainless steel welders investigated in this study were exclusively using the TIG welding method implying very low exposure. Stainless steel welders using other welding methods may be exposed to much higher levels of toxic metals. ${ }^{1}$

Considerable evidence has accumulated that links reduced semen quality with impaired ability to conceive independently of female factors. ${ }^{20}$ The biological significance of a decrease in semen quality due to welding is primarily a risk of infertility and results from several studies support this hypothesis. A case-control analysis of the self reported reproductive experience of 672 male metal workers showed an increased risk of delayed conception (more than two years) in relation to welding. ${ }^{5}$ Another study of about 4000 couples found a significant association between welding of mild steel and delayed conception (more than one year). ${ }^{3}$ Recently a cohort study of 3702 male metalworkers with 47674 years in the follow up period showed a slightly reduced fertility associated with paternal welding exposure. ${ }^{6}$

Considering the extensive application of welding throughout the world with exposure levels often far above those encountered in this study, there is need for further studies. Longitudinal designs investigating semen quality before and after exposure in populations with homogeneous welding exposure are preferable.
This study was supported by grants from the Danish Work Environmental Fund (1985-34 and 1986-35) the Research Council of Nordjyllands Amt, and the Heinrich Kopp Research Fund.

Professor Jørn Olsen, Dr Jens Peter Johansen, and professor Niels Erik Skakkebaek are gratefully acknowledged for valuable discussions. The author is indebted to the participants, who cooperated generously and thereby made this study possible.

Requests for reprints to: Jens Peter Bonde, MD Department of Occupational Medicine, Hospital of Aalborg, Postboks 561, 9100 Aalborg, Denmark.

1 Stern RM. Process-dependent risk of delayed health effects fori welders. Environ Health Perspect 1981;41:235-53.

2 Stern RM, Berlin A, Fletcher A, Hemminki K, Jarvisalo J, Teto $\mathrm{J}$. International conference on health hazards and biologicalo음 effects of welding fumes and gases. Int Arch Occup Environ Health 1986;57:237-46.

3 Rachootin P, Olsen J. The risk of infertility and delayed conception associated with exposures in the Danish worke place. J Occup Med 1983;25:394-402.

4 Mortensen JT. Risk for reduced sperm quality among metal $\stackrel{\varrho}{+}$ workers, with special reference to welders. Scand J Work $\vec{\bullet}$ Environ Health 1988;14:27-30.

5 Bonde JP. Subfertility in relation to welding. A case-referento study among male welders. Dan Med Bull 1990;37:105-108.

6 Bonde JP, Hansen KS, Levine RL. Fertility among Danish male welders. Scand J Work Environ Health (in press). 7 Jelnes JE, Knudsen L. Stainless steel welding and semen quality.

8 Langård S, ed. Biological and environmental aspects of chromium. London: Elsevier Biomedical, 1982.

9 Knudsen I. Mammalian spot test and its use for the testing of potential carcinogenicity of welding fume particles and hex $-\vec{F}$ avalent chromium. Acta Pharmacology and Toxicology음 1980;47:66-70.

10 Danielsson BRG, Dencker L, Lindgren A, Tjälve H. Accumulation of toxic metals in male reproduction organs. Arch Toxicol 1984; [suppl 7]:177-80.

11 Seth PK, Nagar N, Husain R, Chandra SV. Effects of manganese on rabbit testes. Environmental Physiology and Biochemistry 1973;3:263-7.

12 Procope B-J. Effect of repeated increase of body temperature onc human sperm cells. Int J Fertil 1965;10:333-9.

13 Belsey MA. In: Eliasson R, Gallegos AJ, Moghissi KS, PaulsenCA, Prasad MRN, eds. WHO laboratory manual for the examination of human semen and semen-cervical mucus interaction. Singapore: World Health Organisation, Press Concern, 1980 .

14 Statistical Analysis Systems Institute Inc. SAS User's Guide: Basics. 5th ed. Cary, North Carolina: SAS Institute Inc, 1985. I

15 Statistical Analysis Systems Institute Inc. $S A S$ User's Guide: Statistics. 5th ed. Cary, North Carolina: SAS Institute Inc,
1986 .

16 Wyrobek AJ, Gordon LA, Burkhart JG, et al. An evaluation of human sperm as indicators of chemically induced alterations $N$ of spermatogenic function. A report of the US environmental $N$ protection agency gene tox program. Mutat Res 1983;115: $\omega$ 73-148.

17 Schwarts D, Laplanche A, Jouannet P, David G. Within-subject variability of human semen in regard to sperm count, volume,, total number of spermatozoa and length of abstinence. $J_{\Phi}$ Reprod Fertil 1979;57:391-5.

18 Makler A, Zaidise I, Paldi E, Brandes JM. Factors affecting ?+ sperm motility. I. In vitro change in motility with time after ejaculation. Fertil Steril 1979;31:147-54.

19 Matsumoto AM, Bremmer WJ. Endocrinology of the hypo- $\overrightarrow{\mathbb{D}}$ thalamic-pituitary-testicular axis with particular reference to $\stackrel{\rho}{\mathcal{P}}$ the hormonal control of spermatogenesis. Baillière's Clin $\mathbb{Q}$ Endocrinol Metab 1987;1:71-87.

20 Macleod J. Semen quality in one thousand of known fertility and in eight hundred cases of infertile marriage. Fertil Steril 1951;2:115-39.

Accepted 28 February 1990 